\title{
The United Nations Sustainable Development Goals: a setting for Professional and Research skills
}

\author{
Neil Gordon ${ }^{1} \&$ John Dixon² \\ Department of Computer Science and Technology, University of Hull, Hull,HU6 7RX, U.K.

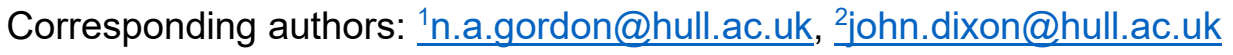

Keywords: Sustainable Development; Social awareness; Graduate Attributes; Research Skills; Computer Science Education

\begin{abstract}
This paper considers the use of the United Nations global goals to provide a framework for the teaching of professional and related skills. The main example and case study considered in this paper is from computing; however, much of the approach and many of the issues are applicable to a wide range of subjects, especially in science. Alongside the specific skills attached to sustainability, the paper also considers the broader development of some of the investigative and analytical skills that underpin university research and reflect the need for a research informed curriculum, and the so-called teaching-research nexus. The paper also considers other aspects of the context for graduate skills, including accreditation requirements and employers' expectations; such expectations of graduates frequently include the requirement that students are able to understand and demonstrate a range of non-technical specific issues, topics and skills and issues. This paper describes the use of global challenges to motivate the delivery and engagement with a case study.
\end{abstract}

\section{Introduction}

The United Nations Sustainable Development goals provide a set of challenges, intended to enable a better future (U.N., 2019). These goals are summarised below, and offer a range of topics and challenges that can be considered in the context of university education, as problems to be addressed by students. Education is recognised as one of the paths to support sustainable development (UNESCO, 2015).

Professional Skills, ethics and related skills are expected within many science programmes, and are typically specified within both Quality Assurance Agency benchmarks (QAA, 2019), as well as within accrediting and professional bodies guidelines. This is particularly relevant within computing degrees, where they are identified within the Association of Computing Machinery (ACM) computing curriculum (ACM, 2019), the IEEE code of ethics and professional practice (IEEE, 2019), and are an explicit requirement for British Computer Society accreditation (BCS, 2019). Similarly, there is a growing need and expectation that students will have developed research skills (reflecting the research informed university) and also commercial awareness, with an appreciation of both risk and the opportunities of enterprise (Nabi et al, 2017). The challenge when teaching is how to motivate students for material that can be considered as ancillary to more technical content. This paper considers how global challenges can provide a framework for developing and contextualising these skills, and is based upon experiences from teaching such material to large cohorts of 
200 or more first year students in Computer Science, but is relevant to many science and engineering disciplines.

The range of issues, topics and skills include:

1) Legal, Social, Ethical and Professional (LSEP) topics. These are identified by the British Computer Society (BCS, 2019) and Association of Computing Machinery (ACM, 2019) graduate expectations. These also reflect the IEEE code of ethics and professional practice (IEEE, 2019). Legal appreciation encompasses a wide range of laws that affect the practice of a computing professional. The social aspect should consider the impact on society of information systems, which goes beyond legal responsibilities. Ethics can provide a framework within which to make choices and judgements. The professional aspects reflect the expectations of practitioners, as developed by recognised industry and sector representative bodies;

2) Appreciating the nature of research and being able to apply analytical and reporting techniques in understanding and carrying out research. These skills are important in assessing the meaning and validity of news and other technical reports, as well as in developing the skills for those going on to commercial R\&S or academic research (Cooke, 2017);

3) Developing team skills and understanding the broader range of activities that a practicing (computing) graduate may carry out in commercial practice. Science courses - especially computing - are frequently more vocational disciplines: graduates would generally anticipate working in the field, and applying (some of) their technical skills. This requires a wider understanding of the commercial and societal context of where they may work and what they may do. Given the emerging technologies and rapid changes, developing graduates that can identify risk, manage projects and develop and launch new initiatives is essential (Leshner \& Scherer, 2019).

This paper initially looks at professional and commercial aspects, the theme of sustainability and the UN notion of Sustainable Development. It goes on to consider some of the curriculum design aspects of professionalism and sustainability topics, before the specific case study is explored.

\section{Professional, Research and Commercial issues \& Skills}

\section{Professional issues}

As described above, various bodies have identified the need for an appreciation and application of Legal, Social, Ethical and Professional (LSEP) topics as expected graduate attributes. Whilst these LSEP topics are clearly defined in terms of professional bodies, the appreciation and understanding of them by faculty and students is more varied (Polmear et at, 2018): it is not uncommon for students to misunderstand all of them, and to have difficulty in addressing them in a given project and scenario, even where a cursory examination shows they do apply.

\section{Research and analysis skills}

The research-teaching nexus is another area that has mixed understanding by faculty and students, and that is not always clearly articulated in (teaching) practice (Wood, 2009). One way to embed and make this concrete is in ensuring that students routinely meet - and develop - an appreciation of the nature of research and develop the skills to be able to apply analytical and reporting techniques in carrying out small-scale research. Related to both LSEP and research is to develop a more complete understanding of academic practices and procedures: helping to, for example, reduce unintended plagiarism and thereby improve the quality of work (and marks).

\section{Commercial Skills}

Given the strong vocational nature of STEM subjects, and the significant and growing demand across the economy for skilled STEM graduates, there is an expectation that such graduates can apply their skills within commercial and industrial contexts. This can enhance the employability of graduates 


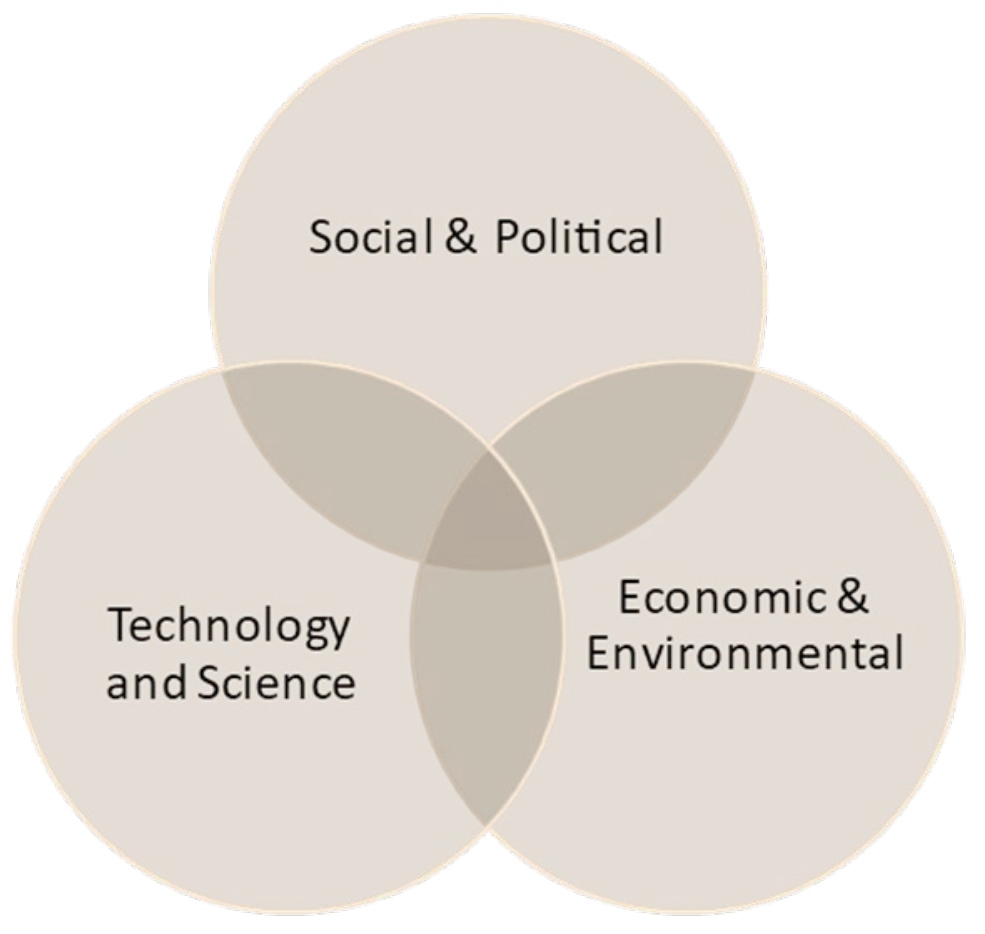

Figure 1 Sustainable topic areas

(Owens \& Tibby, 2014). In computing this means developing students who can build viable solutions; such students need to appreciate the risks in software development, understand the practical issues around project management, and to be able to demonstrate the abilities and skills to develop novel solutions and to exploit them in a commercial way

Motivating this wide range of content, which some- both faculty members and students consider ancillary to their discipline - can be a challenge. However, as illustrated in Figure 1, the range of areas that are encompassed by sustainability can provide contexts to situate and motivate such learning, as discussed in the following section.

\section{Sustainability}

\section{A definition of sustainability}

With the modern surge of ecological value, laws and initiatives it is easy to reduce the topic of sustainability to "green" or eco-centric practice. However, realistically, the topic is far more wide ranging, and can provide a suitable foundation from which to build on legal, social and ethical concerns. It is also a topic which, when studied and considered in depth, can help to encourage students to take a more professional and considered approach (Gordon, 2009).

Considering sustainability from an ecological viewpoint certainly offers significant pause for thought, especially from the perspective of a computer scientist, and this viewpoint is reflected in aspects of the case study below where the ecological impact of computing is considered as one of the challenges to address. Clearly, the rise in technology has had a dramatic impact on the consumption of electricity worldwide and, unsurprisingly, the result of this is that more electricity is required. An increase in electricity demand has, historically, been coupled with amplified pollution levels through the burning of fuels or generation of toxic and radioactive substances. However, slowly, technology is also helping to reduce both the appetite for electricity and the negative impacts of its production through power-saving processes and components, and environmentally friendly power generation methods.

However, it is important to count the costs of a society so used to consuming technology from 
other ecological viewpoints. Whilst we recycle plastics, metals and card, peripherals, machinery and outdated physical technologies tend to be much harder to recycle or reuse. Couple that, with the often highly polluting chemicals that are often used in components and, understandably, the ecological cost of computing, or, more accurately, the detrimental by-products of computing in a throwaway culture, quickly add up. However, moving away from sustainability as a singularly eco-conscious pursuit, it is also important to understand sustainability in other terms, such as society, finance, professionalism and, at least in the area of computer science, sustainable and maintainable software and hardware.

A sustainable society is, broadly, a culture or population which can continue to operate and function, given its current state, its rules and laws and the activities of the populace. This is well captured in the Bruntland (1987) report, as

\section{"development that meets the needs of the present without compromising the ability of future generations to meet their own needs".}

Whilst a sustainable society can be hard to quantify, given the flexible and ever-changing state of the world, shifts in public perception and the large number of unknown variables and consequences. However, largely the sustainability of a society can be broken down into the sustainability of its constituent parts. Financial sustainability is, it is argued especially by capitalists, one of the most important aspects of sustainability as a whole. Consider the simple fact that, for an individual to live, a business to survive or even a government to continue to function, it must eventually balance the books by equalising or improving the ratio of incoming to outgoing funds. This has clear consequences for the decisions made by these entities - it may be a nice idea for a company to give away all its products for free, but it is ultimately an unsustainable endeavour unless there is an alternative stream of funding. It is important that education understands and promotes an appreciation of this, as it can be easy to become complacent with the use of services, which appear free to the user. This is particularly important now in the computer science industry, where data and software services have become so highly valued that companies are able to operate sustainably by offering free services to end users whilst leveraging the collected user data. This is also relevant to software piracy and Intellectual Property Rights - and this topic provides some interesting discussion points with students who often espouse very liberal ideas around copyright and the availability of free software and media content: something we will explore in the case study below.

So now to professional sustainability and ethical or moral considerations. Again, these topics weigh heavily in financial and societal sustainability but are more specific and targeted. Professionalism is highly valued by most businesses because it helps the organisation to remain sustainable and is highly valued by many customers, whose impression of the individual or company is often key to its sustainability. Companies may implement this through their mission statement, company values or through codes of practice. This is sometimes through mandating or encouraging that employees are members of relevant professional bodies that further define professional behaviours and values. Increasingly, individuals and organisations are judged by their ethical character or the morals that they display, and it has never been easier for news to spread about unethical practice or morally questionable actions.

So then, it is clear that sustainability isn't simply a topic dedicated to global ecological concern. It should also be evident that computer science has a huge role to play in both impeding and solving globally sustainable development. By considering and discussing our place as practitioners in all areas of sustainability, Legal, Social, Ethical and Professional (LSEP) topics can be identified, scrutinised and taught, naturally fostering the development of an appreciation of their impact.

\section{Sustainable Development: A Global Challenge for Computer Science}

The range of topics of sustainability considered above fall within the well-defined area of Sustainable Development as advanced by the 
United Nations. Sustainable Development's first international recognition started in the 1960s and 1970s, being further defined in the 1980s (Brutnland, 1987), and has been an explicit theme for the United Nations since 1992, where the UN began to develop an agreed action plan (UK SD Commission, nd). UNESCO developed its aligned initiative, of Education for Sustainable Development (ESD), which was embraced - to a lesser or greater extent - by many countries, such as the U.K. where the Higher Education Academy promoted it through general and discipline specific projects. Sustainable Development itself has now developed into a set of 17 goals (U.N., 2019), which encompasses the areas of:

\author{
i. eliminate poverty; \\ ii. combat hunger; \\ iii. ensure health \& well-being; \\ iv. improving Education; \\ v. enable gender equality; \\ vi. provide clean water and sanitation; \\ vii. source clean energy; \\ viii. enable decent work and growth; \\ ix. develop sustainable industry, \\ innovation and infrastructure; \\ x. reduce inequality; \\ xi. provide sustainable cities and \\ communities; \\ xii. manage responsible production and \\ consumption; \\ xiii. support climate action; \\ xiv. ensure clean oceans and rivers; \\ $\mathrm{XV}$. protect and clean the land; \\ xvi. enable peace \& justice and strong \\ institutions; \\ xvii. partnerships to develop the goals.
}

These 17 goals cover a multitude of topics and issues, many of which are directly affected by - or amenable to improvements through computing technologies, and through STEM subjects in general.

With the focus on how computing can be aligned with this, the issues of the utilisation of resources in a sustainable way, the appropriate use of science (i.e. technology) to inform such use, and the impact of computing on the various goals can be considered as part of system design and development.

Computer Science offers the potential to develop systems, which reduce resource demand e.g. replacing travel with teleconferencing; saving paper by use of on-line document exchange; developing "smart" energy systems. These are illustrated with examples of practice - with eBooks and other online module resources in teaching, and giving examples of practice such as virtual presentation at conferences and within modules for team presentations. For example, social media platforms that do not protect and promote equality could be seen to contravene goals ii, $v$ and $x$. The impact of $A l$ and robotics may be seen as contrary to goals viii and $\mathrm{xi}$, depending on how their impact is managed. Equally, an intelligent power grid, supported with intelligent transport and logistics, would support goals vii, ix, xi, xii and xiii. As both a solution and a contributor to the problem makes it important to understand the connection between Sustainable Development and the many facets of computing. Ensuring our students have this understanding then becomes a duty for educators.

\section{Sustainability and}

Professionalism in the curriculum "Making IT good for society" is the aim proffered by the British Computer Society (BCS, 2019). This, they break down into four challenge areas. The first three: Health and Care, Personal Data and Education are key areas in which we must strive to both increase the usability and usefulness of technologies. The final challenge area is Capability. Capability: the opportunity for good people, with the right skills, in the right role, with the right team to have a positive impact on society. It is in this area that an early focus must be made in order to furnish computer science graduates with an ability to tackle the other challenges afforded to them.

Undoubtedly, it is important that to successfully apply capability, one must also be competent. Competence involves subject-specific knowledge, understanding, practical skills and the application of those skills; but if we accept that capability involves ensuring that people 
are able to use their skills as part of a team then we must recognise that it is also our duty to instil and promote professional skills in addition.

Many professional bodies explicitly define professional guidelines and offer charters, to which members agree to adhere. These statutes encompass the LSEP topics and provide a very useful starting point from which to interrogate global challenges around the subject area and conduct post-mortems on case studies where errors have been made.

Traditional professional proficiencies are also of obvious importance too. Soft skills, such as the ability to communicate effectively, manage time efficiently and utilise social and emotional intelligence, have a huge part to play in enabling an individual to successfully integrate and cooperate with a team or engage in productive client interaction. In academia, showing or promoting acquired knowledge through paraphrasing, quoting or reuse without falling into the trap of plagiarism is managed with rigorous referencing and yet getting this right is found particularly difficult by a number of students. These side-subjects are often thought of as superfluous or tedious by students and, much like an equation taught in isolation of its purpose, quite rightly seem inconsequential.

However, through an appreciation of sustainability as a more complex and multifaceted problem, which is directly linked to legal, social, ethical and professional challenges, an understanding of the importance and impact of skills and abilities can be developed which link directly to the root causes of the issues. It is, for example, possible to explain that encryption helps to keep data secure but with a discussion of data privacy, software piracy and the impact of the negative side of these issues, an ardent appreciation can be fostered as to the purpose, usefulness and potential pitfalls of the encryption technologies that perhaps may invigorate the conception of real solutions to remaining challenges.

\section{Sustainability topics in the Computing Curriculum}

\section{Example topics}

Areas that fit well within the sustainability context described above, and that bring these alive within the computing curriculum, include the following. Of course, within a teaching context, students should be encouraged to identify their own.

One area with both legal and social consequences is the use of data. This can be explored from the perspective of the impact on notions of privacy and the rise of data-veilance, especially with social media and the willing sharing of data, without always appreciating its potential misuse (Cadwalladr \& GrahamHarrison, 2018). This can be illustrated by examples of how institutions now monitor student activity, and use that to help make interventions with students who seem to not be engaging with their studies. There are also some good examples that illustrate the dangers of over-sharing data, such as the PleaseRobMe website (PleaseRobMe, 2010).

The societal aspects of social media include the harm that can be caused, through cyber bullying and cyber-stalking, whilst the new mediums for publishing content, with nonmediated content, means that blogs and the concept of the Post-Truth era are good areas to explore (Hobbs, 2017). These have dimensions around the professional and ethical responsibility - simply because we can design and build open and non-managed platforms, should we, and where does the responsibility lie for any mis-use. Combined with the wider issues of Intellectual Property Rights (IPR): ownership and recognition, this leads to the area of what value and to who does society attribute ideas, data and the software that underpins it all.

The economic, political and personal value of data means that data protection, hacking and cybersecurity are key aspects of how we build sustainable computing systems. As more data and services move to the cloud, there are increasing concerns about where data resides, who provides access to software services, and what is the environmental impact. The growth and widening use of the Internet of Things 
means that more and more devices are now online, and the associated growth in data and possible unintended consequences of its analysis, places new responsibilities on computing professionals. The movement of data, and the location of services, combined with the radical changes these can cause on existing structures - for example the transition of traditional shopping to online shopping, with a small number of global leaders - reflects the way that the internet and cloud computing can be seen to be a catalyst or tool for Globalisation (Polaco \& Backes, 2018).

Computers and society have several aspects, from the concerns about internet use and computer games and health and well-being, as well as the potential digital divide between those able (educationally, financially as well as from a perspective of choice). Developing from this, the impact of computing on work, and the increasing impact of $\mathrm{Al}$ and robotics, means that there is a significant question over what it means to be human. The development of Virtual Reality, Augmented and mixed reality is creating new ethical questions around the impact on users, and even the sense of self. Linked to that, are questions about the ethics of machine rights, as we consider the emergence of sentient (like) machines.

With embedded software systems integrated into the world around us, with the use of software to control vehicles (from autonomous cars to the pilot aids on planes), medical machinery and nuclear power plants, there is a growing need to use software engineering and effective professional practice to ensure Safety Critical software is dependable, given the many safety critical applications and the issues where it goes wrong.

As discussed earlier, the environmental impact - energy usage, material usage, waste disposal - of IT is huge, though needs to be considered and balanced against where it can improve the overall challenges of each of these areas e.g. if systems can make transport and energy usage more intelligent and efficient, then that may more than off-set the direct energy use of the systems themselves.

\section{Pedagogic Approaches to Sustainability in the Curriculum.}

\section{Problem and Inquiry Based Learning}

Problem and inquiry based learning offer ways to get students to engage with assessment activities. Setting authentic tasks can assist students in appreciating the broader context of their discipline and to give them the opportunity to apply their subject specialisms in a real world (like) contexts.

Sustainable Development related problems can be particularly attractive from this perspective. Having established the issues and let the students explore the problem topic and produce a collective view and solution. (Gordon \& Brayshaw, 2008).

In the case study below, we use open ended problems and invite students to identify their own topic. We encourage students to investigate open data, such as that available through the data.gov website (Great Britain, 2020).

\section{Team Work}

Teamwork can be particularly effective in this type of material, especially in the context of modules of hundreds of students. It can encourage and develop the softer skills, and can be an effective way to enable some of the more labour-intensive (from a teaching and assessment perspective) activities such as giving feedback on draft reports, or analysis of news items or research papers.

Teamwork does create some issues in a learning and assessment environment: students are sometimes concerned about freeloaders, and not getting the mark they (believe they) deserve. Approaches to manage and address this include suitable audit of activity, as well as mechanisms such as peer assessment to allow for individualised marking.

Tactics that can assist in successful teamwork include using the problem based approach students collaborate in teams on complex problems, that benefit from different viewpoints and skill-sets, and that could not be tackled in the given time alone. This is further aided by developing problems that include tasks can allow the team to subdivide activities. Team 


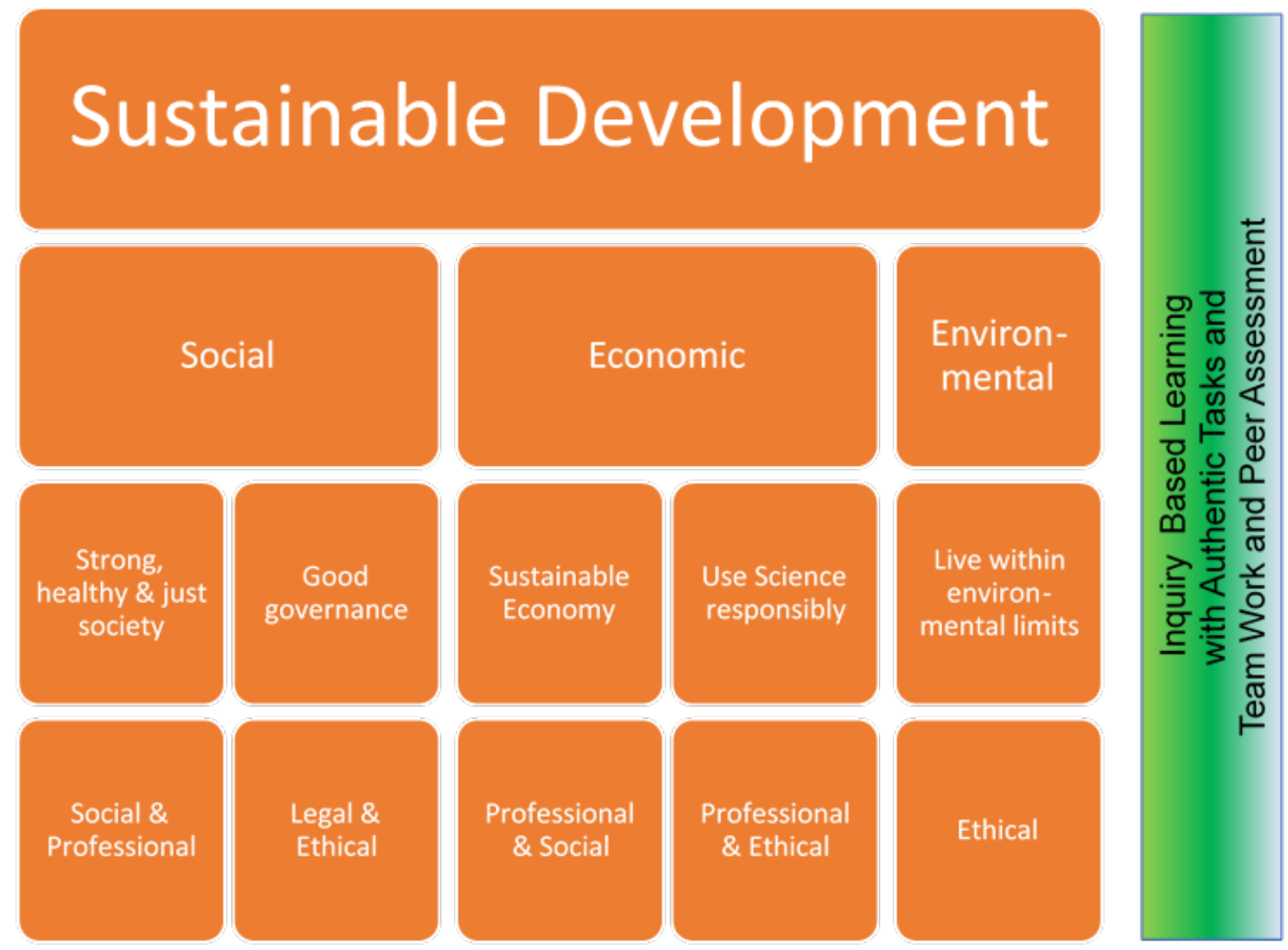

Figure 2 A framework for using S.D. to motivate LSEP. Adapted from Gordon, N (2014).

based activities provide the opportunity to learn about project management and issues that arise in coordinating across tasks and individuals.

In a teaching and learning context, teamwork can be made more effective by ensuring that participants expectations of what is going on are clear, that there are mechanisms to audit and track teamwork, and that offer routes to deal with concerns and issues raised. Audit can be done through VLE group activity tools, online tools such as GoogleDocs, and industry tools such as GIT or SVN. They provide ways to encourage students to collaborate virtually, and to audit activity to provide evidence in the event of issues or appeals.

Whist students may wish - and will - use their own choice of platform e.g. Facebook groups, there should be an explicit official place for summaries of work and for any (copies of) evidence that may be used in the event of team issues. Using tools such as WebPA (WebPA, 2020), students should have a mechanism to submit scores of relative contributions to provide data for academic staff to moderate marks to assign individual marks based on contribution. WebPA collates data to assign individual marks based on teamwork, in a way that students generally find fair and acceptable.

\section{A Framework for Sustainable Development in the Computing Curriculum}

Professional attributes can be mapped onto many aspects of SD. Expectations of social, economic and environment reflect many professional topics. Figure 2 shows a framework that maps the sustainable development pillars and themes into the computing framework for professional and societal awareness. This framework also illustrates where the pedagogic approaches can bridge these to provide a practical approach to teaching and assessing the topics. 
The framework is intended to assist educators in identifying where they can link Legal, Social, Ethical and Professional topics to the UK government's key sustainable themes, and how these map into the 3 pillars of sustainable development identified for the UN Sustainable Development goals. This can assist in identifying example materials through the accrediting and professional needs. The righthand column is to encourage educators to consider authentic approaches - such as IBL in teaching and assessing these, as illustrated in the case study below.

\section{Case Study: Sustainable Computing: The challenge for Computer Science}

This module is delivered as a core module to all level 4 (first year of a 3-year BSc, and related variants). The cohort size has varied between approximately 180 to 320 students. The module was designed to implement the framework in Figure 2, as well as addressing institutional requirements that all degree programmes includes modules that would consider global challenges, and seek to develop graduate attributes, such as team working skills, communication skills, and some evidence of innovation. With a cohort of 300, and challenges with both resourcing and timetabling, we adopted a model of weekly activities, assessed via computer marked quizzes. The quiz content reflected the week's lecture materials, providing a focus for the students to engage with the module content and concepts.

For this Computer Science module, the primary aim was to utilise Sustainable Development, though acknowledging and linking to the more general sustainability topics that students may encounter.

The framework of figure 2 was implemented by selecting a range of topics that enabled the addressing of the U.N. Sustainable topics, as well as a location to explore the LSEP and other topics from the accreditation guidelines. Examples for this included:

1) An introduction to Sustainable Development itself: utilising the background and history of SD as above, along with the definition of sustainability itself, and Sustainable Development according to the UN and UK government;

2) Sustainable Computing as a concept: looking at ecological and financial examples, with the pollution of Ghana by WEE waste providing links to both (Wired, 2020);

3) professional conduct and ethical behaviours for computer scientists: this is illustrated with examples, from the BCS (2021) and ACM (2021) codes of conduct, with examples discussed in lectures and workshops;

4) An introduction to research and research methods, with examples of different forms of published work related to sustainable development and sustainable computing, getting the students to create their own posters on topics, as well as invited lectures, such as a $\mathrm{PhD}$ student under a Commonwealth scholarship able to explain the challenges of internet access in his country and how that related to his own research;

5) Data, Data Analysis and Statistics: examples here include analysing real weather and energy data to look at patterns, and to provide an opportunity to discuss the distinction between correlation and causation, and why absolute proof is such a challenge with this type of real world data;

6) Team dynamics and team working: as a preparation and support for team based activities, we consider different team roles, types of team member and different models for that, such as Belbin and Myers Briggs;

7) Digital Identities: students explore the notion of self when avatars and online persona can be distinct from physical world ones, and the potential problems with identity theft, using some real-world illustrations.

The module assessment was designed for learning (William, 2011), i.e. to encourage 


\section{Activity by date}

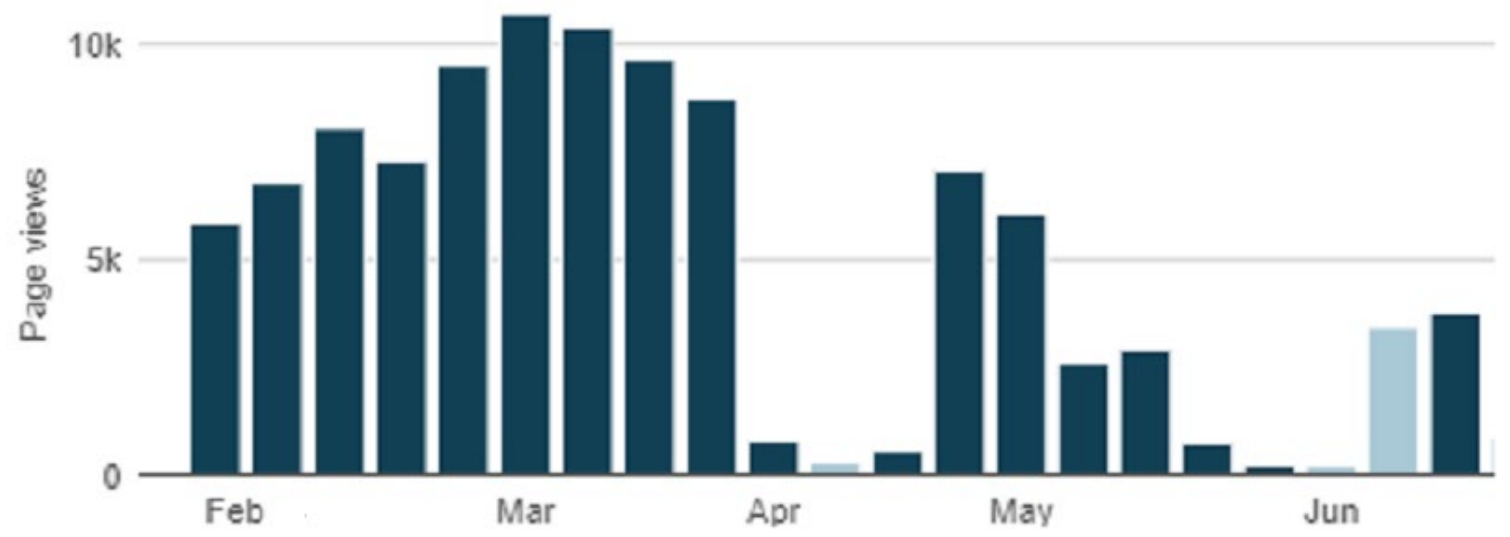

Figure 3 Module site interactions (as indicated by page views)

students to learn by carrying out the suggested work, both formative and summative. This followed from the idea that assessment can be a key mechanism to encourage and direct student activity and focus, where it can have both a formative and a summative (hybrid) role (Gordon, 2010b). The module utilised a range of i) purely formative, ii) purely summative and iii) hybrid assessments.

i) The hybrid assessments were the weekly Computer Based assessments on key concepts - directly aligned with the weekly lecture content.

ii) Purely formative work included peer marking (comments) of posters and paraphrasing of research papers.

iii) The summative work included an inquiry based learning team project - though the process and regular review of student work towards it included formative activity. The poster and team project explicitly utilised the framework in figure 2, being authentic tasks such as presenting ideas in the poster, and carrying out an open investigation in the team project. To allow students more choice, they were able to choose whether the team project was a purely research type activity, or would create a website, app or other artefact.

For the weekly assessments, students were encouraged to discuss and investigate content and questions with peers, promoting collaborative learning. This was done through creating groups within the VLE, and allocating specific student tutors or demonstrators who could engage with their set of teams. To encourage discussion whilst minimise copying, many questions were drawn from a pool, whilst some involved calculations or formula-based questions. Thus, it was not possible to simply guess, nor to copy other student's answers, but students could help one another understand the concepts and then do their individual questions. Immediate feedback on attempts meant that students could gauge their own progress, and seek assistance where they needed it. Thus, the quizzes acted as directed learning and both formative and summative assessment

\section{Course Engagement and effectiveness}

With 200 to 300 students, the overall volume of interaction was high, as illustrated in figure 3, with students participating in online quizzes, using online learning resources, and accessing course support materials. The nature of the assessments and required activities encouraged that. A benefit of the weekly interactions was that these could be analysed to identify students who have not been engaging and may need an intervention to get them back on track for the course. Formative work allows mistakes, plagiarism and poor practice to be highlighted and corrected early, but students don't easily engage as they see it as optional. This module utilised formative peer assessment, e.g. of a writing activity, to 
The United Nations Sustainable Development Goals: a setting for Professional and Research skills

encourage students to consider assessment criteria, as well as to give one another constructive feedback. This was observed from the online discussions and the formative feedback in the VLE.

Strategic extrinsic motivators such as interaction with academic tutors reduced the frequency of non-engagement, reducing the incidence of student responses such as:

\section{"I don't need to do this so I won't bother doing it",}

but rather enhancing engagement, since:

"I know someone is paying attention to my work (or lack thereof) so I will do it".

\section{Conclusions}

Whilst there are general expectations that graduates should understand the wider context of their activities, and should have the necessary skills and graduate attributes to potentially offer a valuable contribution to society, they are not always motivated by this. However, the use of specific examples from Sustainable Computing can provide an effective framework to discuss ethical and professional issues, motivating the topic and encouraging student engagement through an appropriate framework of formative and summative activities, as described in the case study.

Utilising appropriate pedagogic approaches from inquiry-based learning through to suitably framed team work - can provide ways to emphasise the relevance of Sustainable Development to students, as well as making the learning itself more engaging. Tools such as WebPA can make team work - and peer assessment in particular - more acceptable to students, which was apparent from the feedback, where they found the team activity enjoyable and fair. These topics can enable research skills to be explored and practiced. Sustainable Development can provide the basis for problems that provide authentic assessment for students to work on, to enable them to go on to contribute to real-world problems.

\section{References}

ACM. (2019). Curricula Recommendations.

[Online] Available at:

https://www.acm.org/education/curricularecommendations

ACM. (2021) ACM Code of Ethics and

Professional Conduct. [online] Available at:

https://www.acm.org/code-of-ethics

\section{BCS. (2019). Accreditations Guidelines. [online] Available at: \\ https://www.bcs.org/deliver-and-teach- qualifications/university-accreditation/}

BCS. (2021). BCS Code of Conduct. [online] Available at:

https://www.bcs.org/membership/become-amember/bcs-code-of-conduct/

Bruntland, G. (1987). Our common future. The World Commission on Environment 1 and Development, 45-65.

Cadwalladr, C. \& Graham-Harrison, E. (2018). Revealed: 50 million Facebook profiles harvested for Cambridge Analytica in major data breach. The Guardian, 17 March 2018, p.22.

Cooke, N.A. (2017) Posttruth, truthiness, and alternative facts: Information behavior and critical information consumption for a new age. The Library Quarterly, 87(3), pp.211-221. DOI: 10.1086/692298

Gordon, N \& Brayshaw, M. (2008) Inquiry based Learning in Computer Science teaching in Higher Education, Innovations in Teaching and Learning in Information and Computer Sciences, 7(1). DOI: 10.11120/ital.2008.07010022

Gordon, N. (2009). August. Sustainable Development and Social ResponsibilityMaking it Professional. In $10^{\text {th }}$ Annual Conference of the Subject Centre for Information and Computer Sciences (p. 21).

Gordon, N. (2010). Group working and peer assessment - using WebPA to encourage student engagement and participation, Innovations in Teaching and Learning in 
The United Nations Sustainable Development Goals: a setting for Professional and Research skills

Information and Computer Sciences, 9(1).

DOI: 10.11120/ital.2010.09010020

Gordon, N. A. (2010b). Enabling personalised learning through formative and summative assessment. In Technology-supported environments for personalized learning: Methods and case studies (pp. 268-284). IGI Global.

IEEE. (2019). IEEE Code of Ethics. [online] Available at:

https://www.ieee.org/about/corporate/governa nce/p7-8.html

Great Britain. (2020). Find Open Data. [Online] Available at: https://data.gov.uk/

Hobbs, R. (2017). Teaching and Learning in a Post-Truth World. Educational Leadership, 75(3), pp.26-31.

Owens, J. \& Tibby, M. (2014). Enhancing employability through enterprise education: Examples of good practice in higher education. The Higher Education Academy. https://www.heacademy.ac.uk/system/files/res ources/enhancing employability through ent erprise education good practice guide.pdf

Polacco, A. \& Backes, K. (2018). The amazon go concept: Implications, applications, and sustainability. Journal of Business and Management, 24(1), pp.79-92. DOI: 10.6347/JBM.201803_24(1).0004

Nabi, G., Liñán, F., Fayolle, A., Krueger, N. \& Walmsley, A. (2017). The impact of entrepreneurship education in higher education: A systematic review and research agenda. Academy of Management Learning \& Education, 16(2), pp.277-299. DOI: 10.5465/amle.2015.0026

Please Rob Me. (2010). Raising awareness about oversharing. [online] Available at: http://pleaserobme.com/why

QAA. (2019). Quality Assurance Agency. Subject Benchmark Statements. [online] Available at: https://www.qaa.ac.uk/qualitycode/subject-benchmark-statements
Leshner, A.I. \& Scherer, L. (2019). Critical Steps Toward Modernizing Graduate STEM Education. Issues in Science and Technology, 35(2), pp.46-49. https://issues.org/criticalsteps-toward-modernizing-graduate-stemeducation/

Polmear, M., Bielefeldt, A., Knight, D., Swan, C. \& Canney, N. (2018). Faculty perceptions of challenges to educating engineering and computing students about ethics and societal impacts. In Proceedings ASEE Annual Conference (p. 22). DOI: 10.18260/1-2-30510

U.K. Sustainable Development Commission. (nd). History of Sustainable Development. [Online]. Available from: http://www.sdcommission.org.uk/pages/history sd.html

U.N. (2019). United Nations Sustainable Development. [Online]. Available from: https://www.un.org/sustainabledevelopment/s ustainable-development-goals/

UNESCO. (2015). UNESCO. [Online]. Available from:

https://en.unesco.org/themes/educationsustainable-development/what-is-esd/undecade-of-esd

WebPA. (2020). What is WebPA? Available from: https://webpaproject.lboro.ac.uk/

Wiliam, D. (2011). What is assessment for learning? Studies in educational evaluation, 37(1), 3-14. DOI:

10.1016/j.stueduc.2011.03.001

Wired. (2020) Your old electronics are poisoning people at this toxic dump in Ghana. [online] Available at:

https://www.wired.co.uk/article/ghana-ewastedump-electronics

Wood, D. (2009) Challenges to Strengthening the Teaching and Research Nexus in the First-Year Undergraduate Curriculum. International Journal of Learning, 15(12). DOI: 10.18848/1447-9494/CGP/v15i12/46051 